\title{
Ergonomically Designed Workstation for Pregnant Workers in Apparel Industry
}

\author{
Dr. (Prof) Noopur Anand ${ }^{1}$, Dr. Archana Gandhi ${ }^{2}$, Vipul Verma ${ }^{3}$, Sarablin Kaur ${ }^{4}$ \\ I( Professor,Department of Fashion Technology, National Institute of Fashion Technology, New Delhi, India) \\ ${ }^{2}$ ( Asso. Prof,Department of Fashion Technology,National Institute of Fashion Technology, New Delhi, India) \\ ${ }^{3 \& 4}$ ( Students,Department of Fashion Technology, National Institute of Fashion Technology, New Delhi, India,
}

\begin{abstract}
The textile and apparel industry is one of the leading segments of the Indian economy and the largest source of foreign exchange earnings for India. India's garment industry employs about eight million workers, of which 70 percent are women. A significant number of them are pregnant while on job and face discomforts because of long hours of working. Especially the women working in the finishing section of apparel manufacturing set-ups as the job requires them to be in standing posture for long hours at a stretch. This is not only uncomfortable but it also poses threat to pregnancy. Given such a large population of mid-aged pregnant female workers in garment manufacturing setups are facing difficulties in work, very little has been done to address their needs during pregnancy in India. This study was conducted to design a special ergonomic workstation for expectant workers to address their special needs.
\end{abstract}

Keywords: Ergonomics; Pregnancy; Workplace Hazards; Finishing; Re-engineered Workstation

\section{Introduction}

The textile and apparel industry is one of the leading segments of the Indian economy and the largest source of foreign exchange earnings for India. This industry accounts for 4 percent of the gross domestic product (GDP), 20 percent of industrial output, and slightly more than 30 percent of export earnings ${ }^{1}$ (Vern Simpson 2001). The textile and apparel industry employs about 38 million people in more than 60,000 units, making it the largest source of industrial employment in India and 94percentage of total women workers work in informal sector ${ }^{2}$ (Geetika et al 2011). India's garment industry employs about eight million workers, of which 70 percent are women ${ }^{3}$ (Simone Preuss 2013). A significant number of them are pregnant while on job and face many discomforts because of long hours of working, quite many of these hours are in standing posture. It is not only uncomfortable but poses threat to pregnancy. A study Miscarriage and occupational activity: a systematic review and meta-analysis regarding shift work, working hours, lifting, standing, and physical workload, was conducted ${ }^{4}$ (Bonde et al 2012) to evaluate the risk of miscarriage due to prolonged standing and long working hours. It indicated that those who stood for more than 8 hours have a metarisk of 1.26 of miscarriage than those who stood $>3$ hours/day. Another analysis showed that the adjusted odd ratio (OR) for pre-term birth of pregnant workers standing more than 6 hours per day during work was 1.26 and for women standing for 2-6 hours per day and less than 2 hours per day are 1.06 and 1 respectively ${ }^{5}$ (Saurel-Cubizolles et al 2004). Additionally, Naeye \& Peters $(1982)^{6}$ reported that the mean birth-weight of newborns at term was lower when mothers worked in a standing position. Prolonged standing at work has been associated in epidemiological studies with lower extremity (LE) discomfort ${ }^{7}$ (Rayan 1989) varicose veins ${ }^{8}$, (Tuchsen et al 2005) progression of carotid atherosclerosis ${ }^{9}$ (Krause et al 2000) and complications of pregnancy ${ }^{10}$ (Ha E et al 2002).

Given such a large population of mid-aged female workers who may become/or currently are pregnant in garment manufacturing setups and are facing face difficulties in work, very little has been done to address their needs during pregnancy.

\section{Methodology}

With this need to address the challenges faced by pregnant women workers in India a study was conducted to design a special ergonomic workstation for expectant workers. The methodology of the study was in 3 steps as in follows

Step 1-Review of literature

- Ergonomic risk factors in pregnancy

- Body change in pregnancy

- Study of sitting and standing posture in pregnancy

- Prolonged standing and adverse pregnancy outcomes

Step 2- Primary research 
- Management survey: to study female workers demographics and management responsiveness to work place pregnancy

- Expectant worker interview: To asses the task performed, working conditions, ergonomic limits and problems at workplace

- Body map and discomfort analysis using Nordic questionnaire

- Anthropometric measurement of pregnant women for work station design

Step 3- Work Station Design

- Identification of work station to be designed

- Designing \& development of prototype optiond for re- engineering workstation

- Comparative comfort evaluation analysis of developed prototypes.

\section{Current Status Of Pregnant Workers In Indian Garment Industry}

A survey of management as well as pregnant workers was conducted in 10 garment factories with an average worker size of 733 in Tirupur and Bangalore through questionnaires.

The objective of the management questionnaire was to understand the average age, distribution pattern of women workers in the factory and number of pregnant workers. It also aimed at understanding management's responsiveness to maternity health and workplace safety.

The key findings are listed below:

- $79 \%$ of the total workforce were female workers distributed in departments of Sewing, Finishing and Packaging in a descending order.

- $89 \%$ of the female workers were married and $53 \%$ of the female worker population was in the age group of 21-30.

- On an average there were 4 pregnant workers in each factory of which $62 \%$ were still working and were in their 2 nd trimester and $38 \%$ was on maternity leave. Women preferred to work till mid of third trimester i.e. 8th month

- The pregnant women were moved either to the thread trimming section or inspection by the management

- Almost all factories provide Employee State insurance and Health checkup though some factories confessed to having policy of not hiring pregnant women workers. Two of the respondent factories had unique identification mark like a cap, flags, etc. for pregnant operators to address their special need.

- Working days for pregnant women were same as that of non- pregnant female workers - 6 days per week.

- None of respondent factory ever redesigned workstation for pregnant workers.

Another questionnaire was designed for the pregnant workers in the factory to assess the tasks performed, working conditions and problems at workplace for pregnant workers. Twenty pregnant workers with mean age of 27.2 years (s.d. 3.23) were interviewed to conduct this experiment out of which 8 were from sewing department and 12 from finishing department.

The findings indicated that majority of women prefer to work till $8^{\text {th }}$ month of pregnancy. The pregnant workers (like regular workers) worked 9 hours daily with two breaks per shift excluding tea and lunch breaks. The continuously expected stretch of work is for 3 hours and almost all felt fatigue after 1-2 hours of working. The major problem faced by the pregnant workers in the finishing department was increase in reach distance due to growth in the abdomen as bending got restricted. This problem increased as the pregnancy developed with months. Also prolonged standing was found to be a major concern by them which also has adverse effect on the mother and the baby. The results indicated that the workers from the finishing department faced more problems and fatigue as compared to the ones from sewing.

To assess the discomfort faced by pregnant workers in a more precise and objective way, Nordic Discomfort Analysis was done in the both Sewing and Finishing departments.

\section{Nordic Discomfort Analysis In Sewing And Finishing:}

The Nordic Musculoskeletal Questionnaire (NMQ) was developed from a project funded by the Nordic Council of Ministers ${ }^{11}$ (Kuorinka et al 1987). The aim was to develop and test a standardized questionnaire methodology allowing comparison of pain/discomfort in different parts of the body, its severity and interference with the ability to work.

Fourteen pregnant workers (6 from sewing and 8 from finishing) with mean age of 27.2 years (s.d. 3.23) were interviewed to conduct this experiment. The subjects were asked to mark the parts facing discomfort on a body map and its severity. 
In Nordic questionnaire, questions were asked about any kind of ache, pain, and discomfort in various body parts labeled on a body map as shown Fig 1.

For every body part, three scores were collected - Frequency of pain (on an increasing scale of 0-4), Magnitude of pain (on an increasing scale of 1-3) and Interference with ability to work (on an increasing scale of 1-3).A discomfort score was calculated for each part (right body parts distinguished from left) using the formula:

Discomfort Score(D.S.)= Frequency Score X Magnitude Score X Interference Score

And the average for each part was calculated using below formula:

\section{Part wise average discomfort score :}

$=\frac{\sum_{n=1}^{x y} \text { Discomfort Score (D.S.)for respective part }}{x, y}$

Where $\mathrm{x}=$ Sample size of pregnant sewing operators $=6$

$\mathrm{y}=$ Sample size of pregnant operators in finishing $=8$

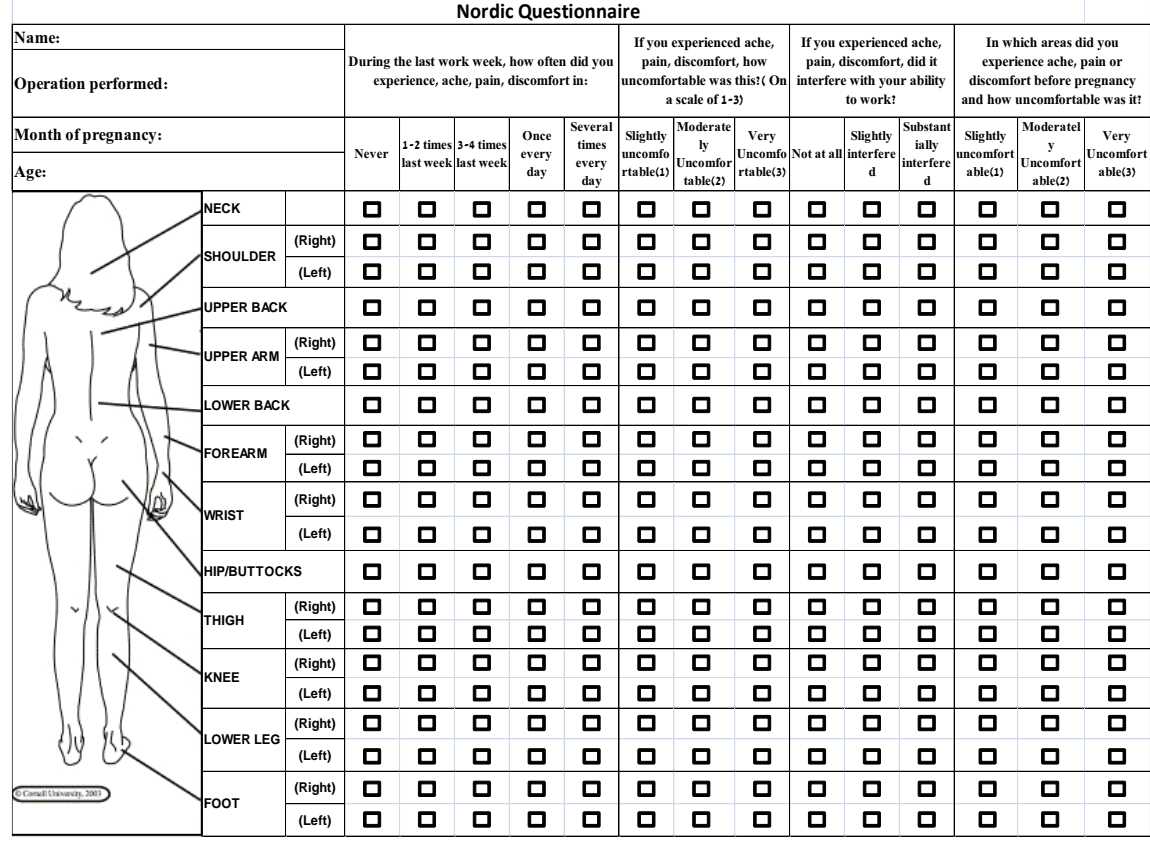

Figure 1: Nordic Body Discomfort questionnaire

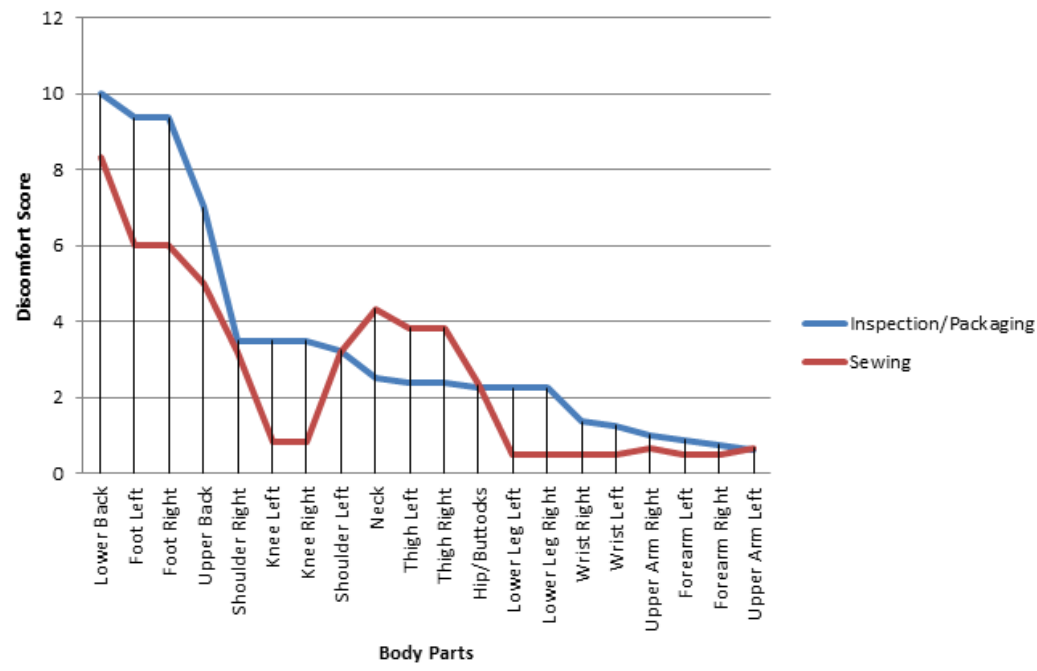

Fig 2: Comparison of discomfort scores for sewing and finishing operators 
The chart in Fig 2 shows the comparison of discomfort scores calculated for various parts between sewing and finishing operations. As it can be clearly seen that for every part except for neck/thigh /hip ,the discomfort is more in finishing operation which is a standing operation. The discomfort is at peak for Lower back and feet. Lower back pain is because of increasing lumbar lordosis ${ }^{12}$ (Simone 2008). As the gravid uterus enlarges, weight gain is concentrated in the lower two-thirds of the trunk causing center of gravity to shift anteriorly, which leads to a tendency to fall forward. To restore the center of gravity, progressive lordorsis occurs when the women unconsciously arches her upper body back over the pelvis and lower extremities which causes the pain.

The discomfort score of foot is also very high. During pregnancy, body fluids increase in order to nurture both mother and baby. As the body tissues accumulate and retain fluids swelling is experienced. Also the growing uterus puts pressure on the mother's pelvic veins and vena cava (the large vein on the right side of the body that carries blood from lower limbs back to the heart). The pressure slows the return of blood from legs, causing it to pool, which forces fluid from the veins into the tissues of feet and ankles causing the discomfort.

This established the fact that the standing operation in finishing posed maximum risk to the expectant worker. This became the focus of the study.

Further, REBA (Rapid Entire Body Assessment), a quantitative assessment tool was used on women of finishing section to validate the findings of Nordic.

\section{Rapid Entire Body Assessment} McAtamney. ${ }^{13}$

The Rapid Entire Body Assessment (REBA) method was developed by Dr. Sue Hignett and Dr. Lynn

This ergonomic assessment tool uses a systematic process to evaluate whole body postural MSD and risks associated with job tasks. A single page worksheet is used to evaluate required or selected body posture, forceful exertions, type of movement or action, repetition, and coupling.

The REBA worksheet is divided into two body segment sections - labeled A and B. Section A (left side) covers the neck, trunk, and leg. Section B (right side) covers the arm and wrist. This segmenting of the worksheet ensures that any awkward or constrained postures of the neck, trunk or legs which might influence the postures of the arms and wrist are included in the assessment. Score Group A (Trunk, Neck and Legs) postures first, then score Group B (Upper Arms, Lower Arms, and Wrists) postures for left and right. For each region, there is a posture scoring scale.

The REBA test was performed on ten pregnant workers employed in the finishing department undertaking the standing operations of Thread Trimming, Inspection and Folding

The Average REBA scores are in Table 1 follows:

\begin{tabular}{|c|c|}
\hline Operation & REBA Score \\
\hline Thread Trimming & 10 \\
\hline Inspection & 9 \\
\hline Folding & 11 \\
\hline
\end{tabular}

Table 1 : REBA Scores for women workers in finishing department

Thus according to the REBA assessment risk analysis scoring, the final REBA scores for both Thread trimming and Inspection operations fall in the interval of 8 to 10, which concludes that the pregnant workers are under high risk. A score of more than 10 in folding indicates that the pregnant workers are under very high risk and there is a requirement to implement change immediately.

This established the extent and area of the problem. Redesigning of work stations were undertaken to address the problem.

\section{Prototype Development}

Several systematic review done in past indicated that prolonged standing has impact on risks of preterm delivery and low birth weight/small for gestational age (SGA).Severe complications of prolonged standing while pregnant, Nordic Body Part Discomfort analysis resulting in high discomfort scores in lower back, foot, upper back and shoulder and further assessment of current workstation for inspection/thread trimming using REBA (Rapid Entire Body Assessment) justifies the need of immediate change because of high risk posed.

The main objective was to convert the standing operation of inspection/thread trimming/packaging to sitting which is also recommended by EU Guidelines for pregnancy and also by Stephen J. Morrissey in 'Work place design recommendations for the pregnant worker' 14 (Stephen 1998)

Seating prototype including a table and three options for chair were developed and further tested. 
Table Design:

The table designed had a feature of an oval cut which was to accommodate the abdomen growth which causes hindrance in reaching to distance. The oval cut on the table just in front of the abdomen reduces the reach distance and hence prevents bending and twisting while performing the operation. Also an inclination of $10^{\circ}$ was given to the table surface to enable the workers to have a clear view of the garment being examined and to maintain postural stability while at work.

The table top dimensions were calculated according to the nature of task to be performed on it. Considering the operation of checking the measurements where you need to lay the garment flat on the table surface, the dimensions were calculated accordingly using trouser as the reference garment.

The table length was calculated keeping the length of the reference garment with 6 inches of allowance (i.e. 3 inches bigger on both sides of the reference garment) is: 6 inches allowance +42 inches (average Large of reference Garment Length) $=48$ inches

The table has a feature of an oval cut which is to accommodate the abdomen growth which causes hindrance in reaching to distance. The oval cut on the table just in front of the abdomen reduces the reach distance and hence prevents bending and twisting while performing the operation.

The dimensions of the oval was calculated using anthropometric data of pregnant females with the following dimensions :

Table Cut Arc $=20$ inches Table Cut Depth $=8$ inches

To calculate table width- the breadth of reference garment in addition to allowance and the table arc was taken. Hence the able width was 18 inches reference garment width +8 inches abdomen curve+ 4 inches allowance $=30$ inches

The table height was kept 28 inches on the basis of anthropometric from pregnant women.

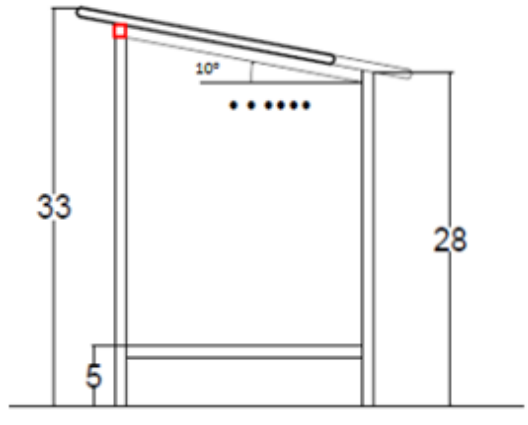

Fig 3 a

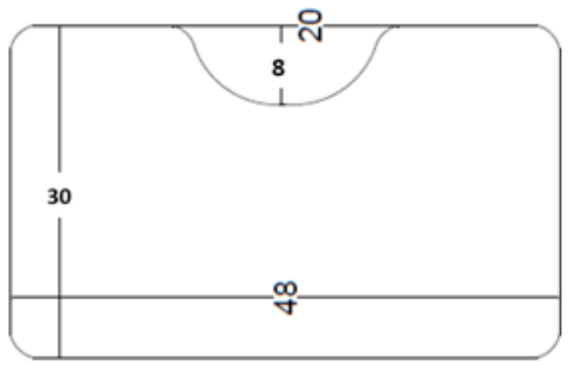

Fig 3b

Fig 3 (a \&b) Dimension of the Table

The oval cut in the front was cushioned with foam to avoid any kind of accident or abrasion from the table edge. Actual ergonomic table designed for pregnant women is shown in Fig 4

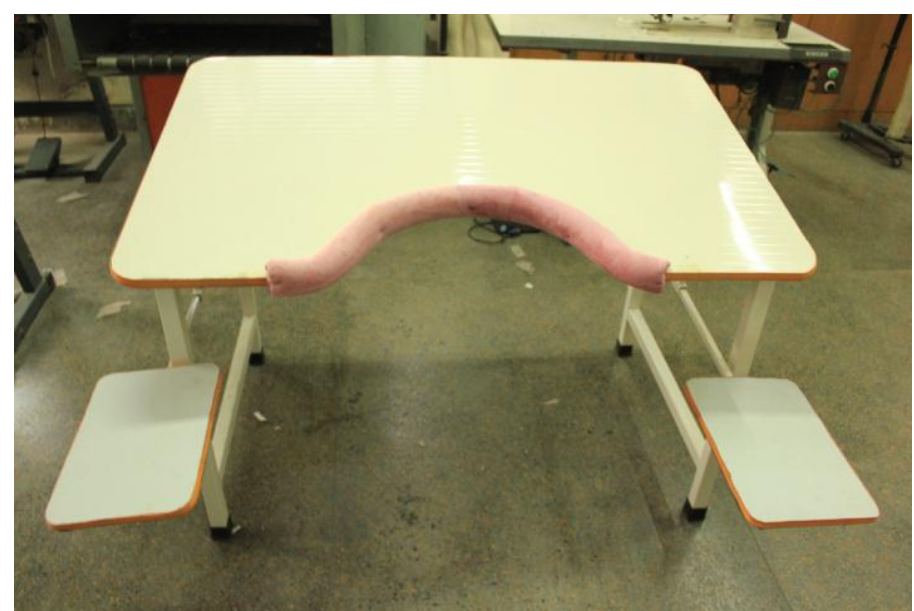

Fig 4 : Actual ergonomic table designed for pregnant women workers of finishing section 
Seating Prototype Design:

The developed Seating chair prototypes have a common feature of front inclination of $10^{\circ}$ to the seat. Forward sloping seats were generated in the ability of the forward sloping seat to counteract the potentially negative consequences of upright seating ${ }^{15,16}$ (Corlett 1999) (Mandal 1985)

Forward inclination decreases the biomechanical loading on the low back, reduces low back and thighs discomfort favors postural adaptations, prevent leg edema by facilitating leg mobility, extends reach, and reinstates lumbar lordosis by tilting the pelvis.

A height adjustable chair with increased seat pan was developed as shown in Fig 5 as per the measurements in Table 2:

\begin{tabular}{|c|c|}
\hline \multicolumn{2}{|c|}{ Table 2 :Measurements of ergonomic chair } \\
\hline Seat length & 18 inches \\
\hline Seat Breadth & 18 inches \\
\hline Min. Seat Height & 16 inches \\
\hline Backrest Length & 19 inches \\
\hline Backrest Width & 18 inches \\
\hline
\end{tabular}

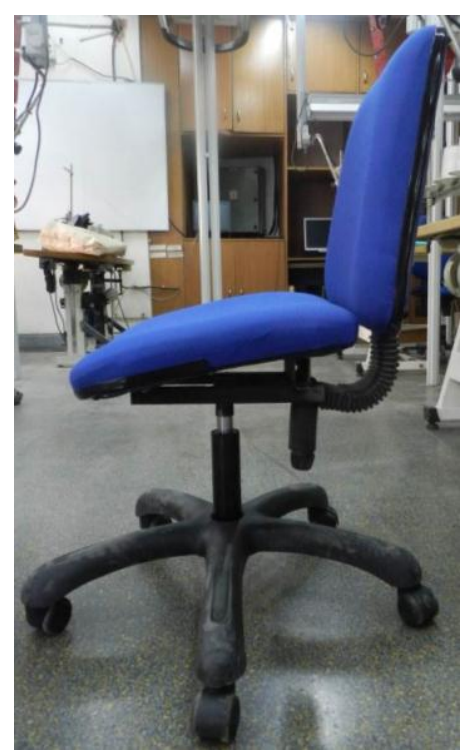

Fig 5: Prototype of Chair A with inclined seat

The same was tested on expectant subjects but was found to have following problems:

- Tendency to slide off the chair

- Increased discomfort in thighs and legs due to greater muscle action required

Shin rest was provided to avoid forward slipping and another prototype B was developed as in Fig 6 and tested, but it was found to have increase the weight load on shin and leg area which already are suffering because of Edema. It also caused constrained posture. 


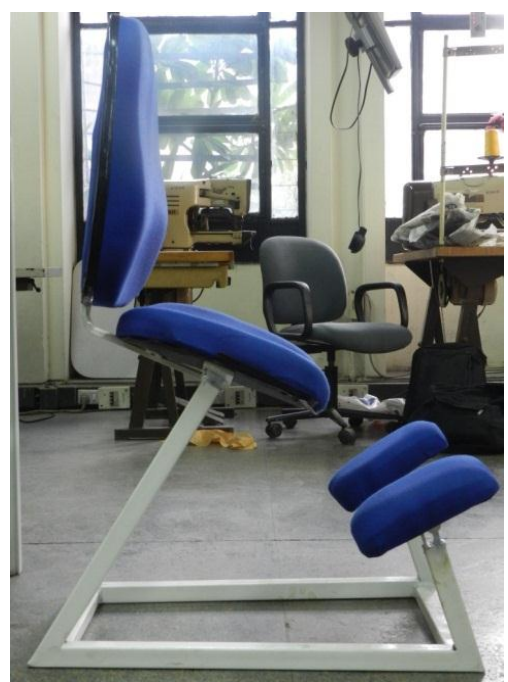

Fig 6: Prototype of Chair B with inclined seat and padded shin rests

To address this issue, the chair was provided with a minimal rocking feature which is user controlled. The rocking feature is proved to have positive effect on the posture of pregnant females. This was also supported by the review of literature which establishes that the lack of movement causes leg swelling during pregnancy ${ }^{17}$ (Winkel et al 1986).During movement, the "expansion and contraction" of the muscles help promote circulation and prevent edema. Hence when seated subjects move about in their seat, they experience much less edema than inactive sitters ${ }^{18}$ (Van Deursen et al 2000). Further, reported that incorporating small but continuous movements into the day increased the time of onset of leg swelling ${ }^{19}$ (Winkel 1981)

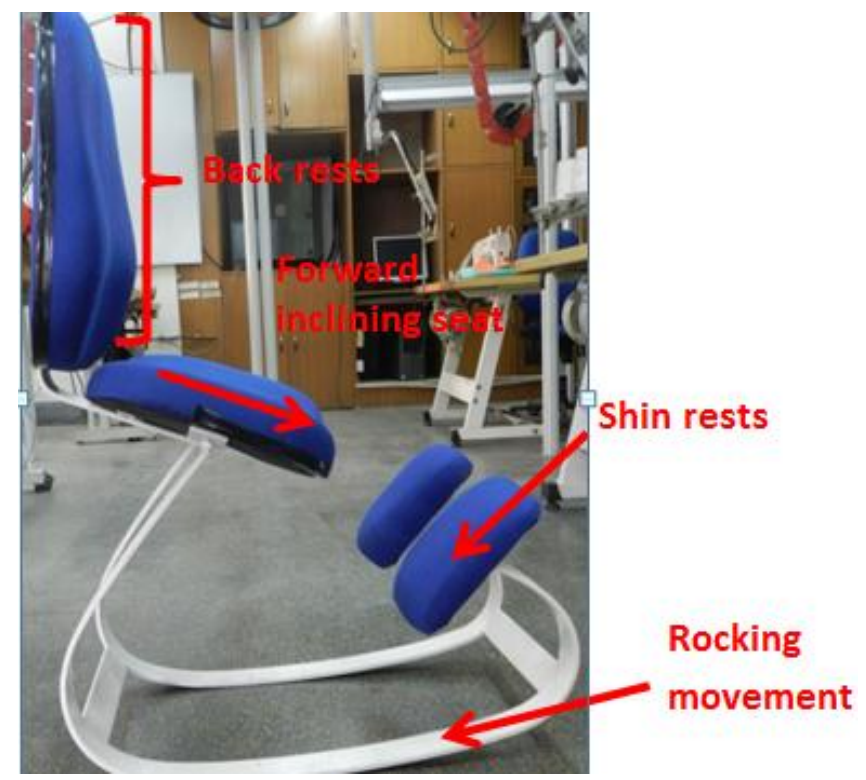

Fig 7: Prototype of Chair $\mathrm{C}$ with inclined seat; padded shin rests and rocking feature

So prototype $\mathrm{C}$ was created having rocking feature was provided to the chair as shown in Fig 7 where the user can rock whenever she wants using her leg. The shown prototype was developed and tested for comfort rating.

The chair was found to be most comfortable and caused minimal discomfort. Another aspect is the ability of the chair to shift the user's center of gravity as they shift position. This important design consideration enables the user to maintain in a stable and centered position as they move.

The final developed ergonomically designed sitting work station for pregnant women in finishing department of apparel industry Fig 8 


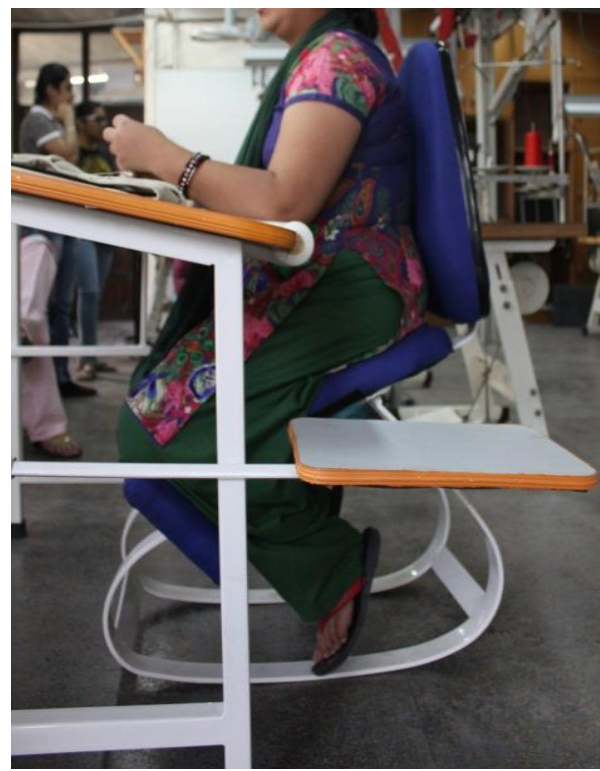

Fig 8: Ergonomically designed sitting work station for pregnant women in finishing department of apparel industry

\section{Conclusion}

The three seating workstations as shown in Fig 9 developed were tested on the 5 pregnant female workers and feedback was recorded.

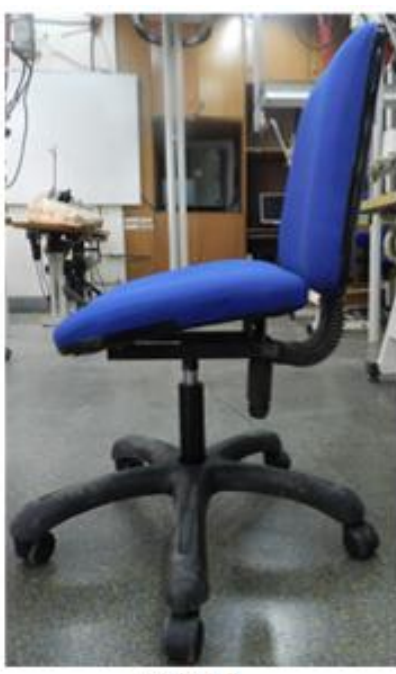

Chair A

Front Inclined chair

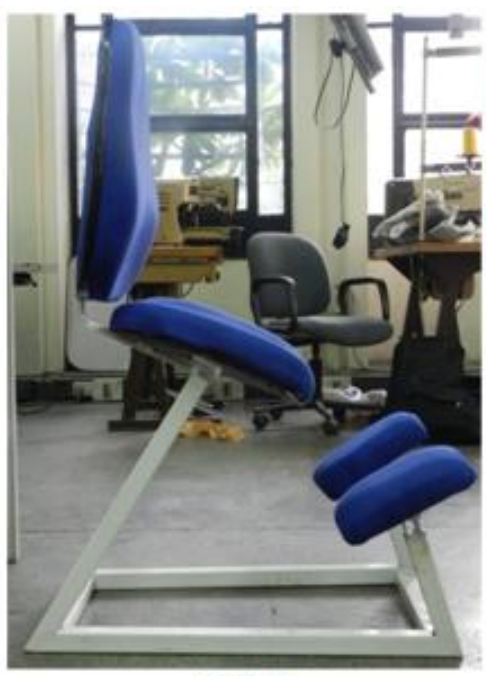

Chair B

Inclined chair with shin rest

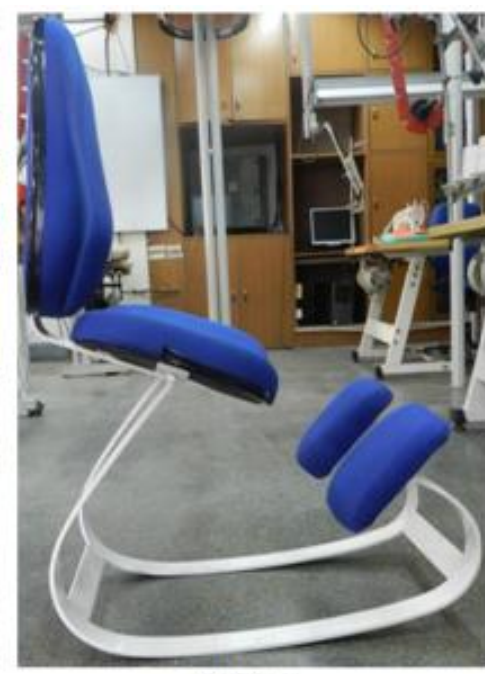

Chair C

Rocking Chair with shin rest

Fig 9: Three seating workstations Prototype of Chair A, B and C

The evaluation was done in three sections:

1. Discomfort Evaluation: The subjects were made to sit on each chair for a period of 3hours for 2 days and after that they were asked to fill body part discomfort table which also inquired about the severity of the discomfort. A discomfort score was generated according to the severity of discomfort for each part with slightly uncomfortable having score of 1 , moderately uncomfortable-2 and very uncomfortable-3. The discomfort Evaluation is shown in Fig 10 


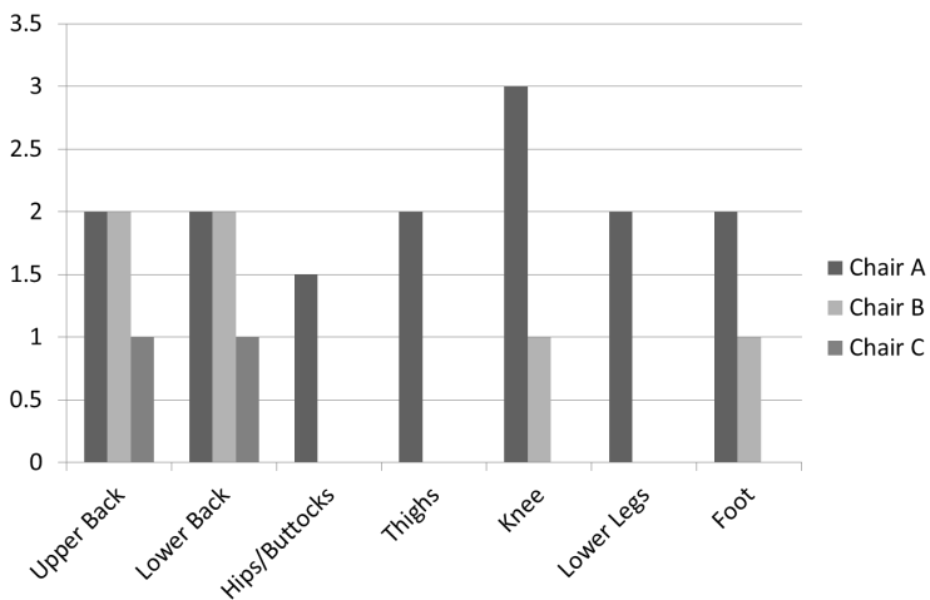

Fig 10 : Discomfort Evaluation in prototype Chair A, B \& C

An overall body discomfort in lower parts like knees, lower legs, thighs and foot was observed in Chair A (Forward Inclined Chair). The possible reason can be the unsupported forward sliding which results in loading of weight on lower body parts. Lack of footrest made sitting on this chair for longer duration difficult. However the discomfort in thighs, lower legs reduced in Chair B because of the support provided by shin rests. The discomfort was found to be the lowest in prototype Chair C.

2. Chair Feature Rating: The subjects were asked to rate various features of each chair like chair height, seat shape, rocking action, position of shin rest, and height adjustability mechanism on a Likert Scale of 1 to 5 .

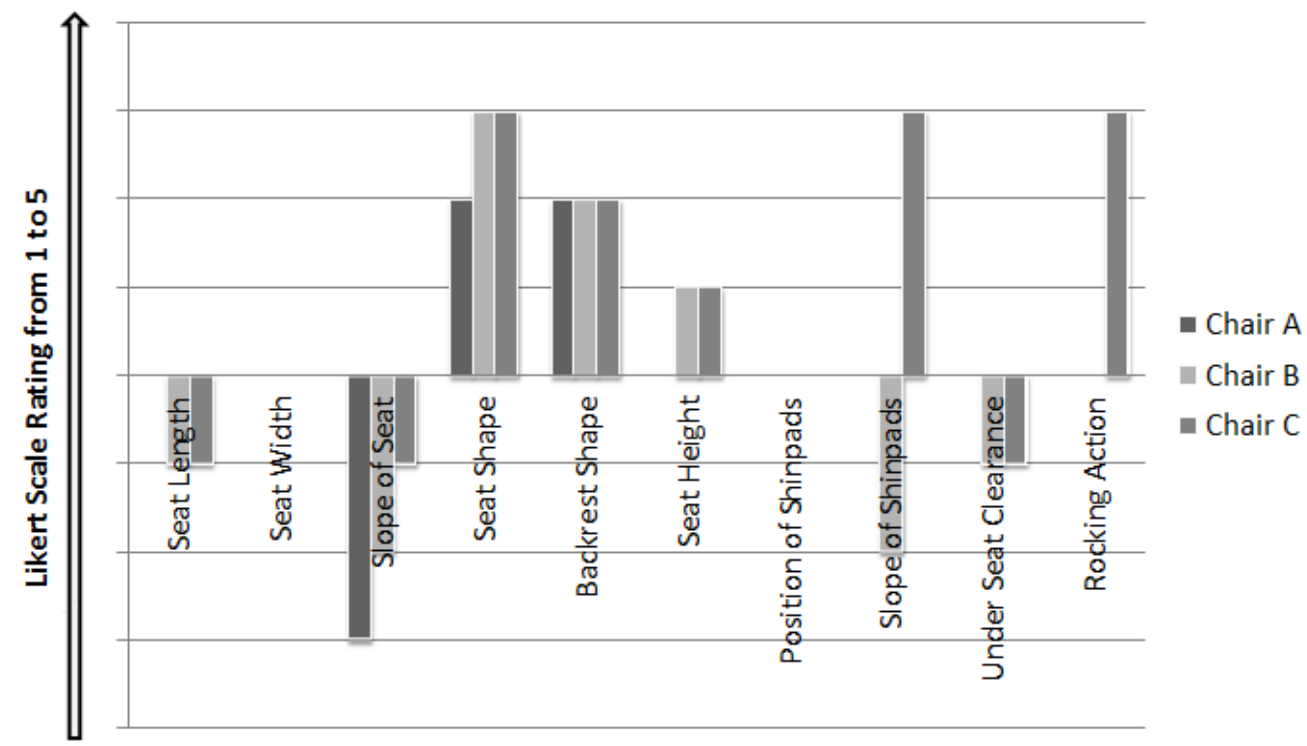

Fig 11: Chair feature rating in prototype Chair A, B \& C

It can be clearly seen that Chair C is rated highest for most of the features evaluated as shown in Fig 11.

3. General Evaluation: This section asked questions about overall comfort, problems faced while getting in or out of chair and the subject's feedback on the chair. The responses were recorded in the form of a chart and are shown below. The graph for Chair $\mathrm{C}$ lies on top of the rest of the two chairs making it most preferred prototype in general evaluation as well. 


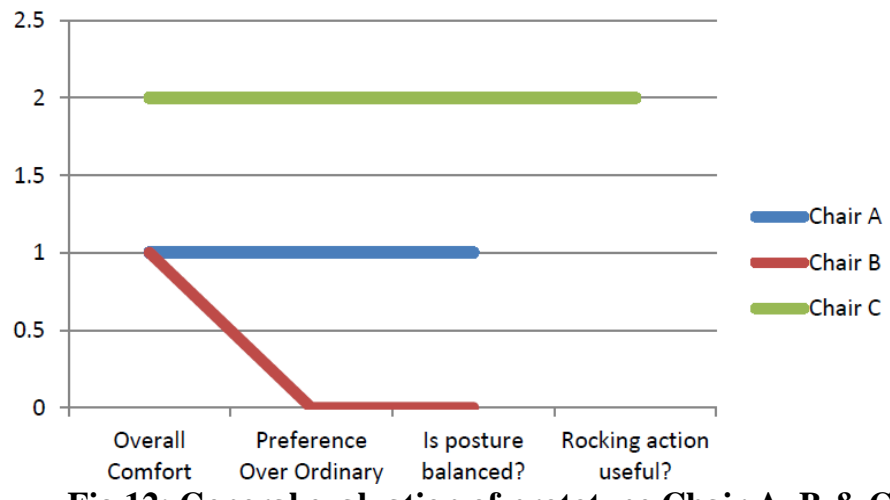

Fig 12: General evaluation of prototype Chair A, B \& C

The created sitting ergonomic workstation of table and prototype table $\mathrm{C}$ was well appreciated.

\section{References}

[1]. Vern Simpson(March 2001) Office of Industries, US International Trade Commission report Textile and Apparel Industry: Growth potential and Trade and Investment opportunities, Washington, DC

[2]. Dr. Geetika, Dr Tripti Singh, Anvita Gupta(2011), Women Working in Informal Sector in India: A saga of Lopsided Utilization of Human Capital, International Conference on Economics and Finance Research, IPEDR vol.4

[3]. Simone Preuss ; Article; Indian garments: second only to textiles (06 November 2013) ww.fashionunited.co.uk/fashionnews/fashion/indian-garments-second-only-to-textiles-2013110618938 accessed on 5th May 2014

[4]. Bonde JP, Jørgensen KT, Bonzini M, Palmer KT. (2012). Miscarriage and occupational activity: a systematic review and metaanalysis regarding shift work, working hours, lifting, standing, and physical workload.Scand Journal of Work Environment Health.

[5]. M J Saurel-Cubizolles, J Zeitlin, N Lelong, E Papiernik, G C Di Renzo, G Bre'artJ Epidemiol Community Health. (2004). Employment, working conditions, and preterm birth: results from the Europop case-control survey. Journal of Epidemiol Community Health. pp 396.

[6]. Naeye RL, Peters EC. (1982) Working during pregnancy: effects on the fetus. Pediatrics; pp 724-7

[7]. Ryan G A. The prevalence of musculoskeletal symptoms in supermarket workers. Ergonomics 32 (1989) pp 359-371.

[8]. Tuchsen F, Hannerz H, Burr H, Krause N. (2005) Prolonged standing at work and hospitalization due to varicose veins: A 12-year prospective study of the Danish population. Journal of Occupational Environmental Medicine

[9]. Krause N, Lynch JW, Kaplan GA et al. (2000) Standing at work and progression of carotid atherosclerosis. Scandinavian Journal of Work Environment and Health pp 227-236.

[10]. Ha E, Cho, SI, Park H, Chen D et al. (2002) Does standing at work during pregnancy result in reduced infant birth weight? Journal of Occupational Environmental Medicine.

[11]. Kuorinka I, Jonsson B, Kilbom A et al. 1987Standardized Nordic questionnaires for the analysis of musculoskeletal symptoms. Appl Ergon; pp 233-237.

[12]. Simone Ho Sin Man (2008). Maternity Garment treatment for the relief of low back pain. Hong Kong: The Hong Kong Polytechnic University. 26 Doctoral Thesis PolyU Library Call No.: [THS] LG51 .H577P ITC 2008 Ho

[13]. Hignett, S. and McAtamney, L. (2000) Rapid Entire Body Assessment: REBA, Applied Ergonomics,pp 201-5 .

[14]. Stephen J. Morrissey (1998) Article Research Gate ; Work place design recommendations for the pregnant worker- International Journal of Industrial Ergonomics

[15]. Corlett, E.N. (1999) Are you sitting comfortably? International J Industrial Ergonomics, pp 7-12.

[16]. Mandal, A.C. (1985) The Seated Man: Homo sedens. Denmark: Dafnia Publications.

[17]. Winkel, J., and Jorgensen, K. (1986) Evaluation of foot swelling and lower-limb temperatures in relation to leg activity during longterm seated office work. Ergonomics,pp 313-323.

[18]. Van Deursen, D.L., van Deursen, L.L.J.M., Snijders, C.J. and Goossens, R.H.M. (2000) Effect of continuous rotary seat pan movements on physiological oedema of the lower extremities during prolonged seating. International Journal of Industrial Ergonomics., pp 521- 526.

[19]. Winkel, J. (1981) Swelling of the lower leg in sedentary work: a pilot study. J Human Ergology, , pp 139-149. 